the first edition appeared in 1836 ; by their numerous contributions to medical literature, and by the teaching of Trousseau, when, after a magnificent concours, about 1835, he took, and held for many years, the chair of Therapeutics in the Paris school.

After taking a Paris degree in 1839, I came to London to walk the hospitals, passing at once from an atmosphere of doubt, scepticism, and therapeutical inaction, to a land where the medical mind was reposing in the undisturbed conviction that it had brought therapeutics to perfection. Had not exorbitant doses of medicine been utterly repudiated? Were there not three national Pharmacopoias to be chosen from, besides the special Pharmacopœia of each large hospital? Had not all this positive pharmaceutical lore culminated in the just published work of Pereira - to be henceforth the bible of British practice? Every medical man I spoketo shrugged his shoulders at the miserable ignorance of therapeutics in the French school; and as I walked round the hospitals I never ceased admiring the wonderful confidence with which drugs were being adminis. tered. But even when all seemed so safely settled, there were thinkers already chafing against a system which ignored entirely the all-healing powers of nature, and they found an exponent in Sir John Forbes, who in 1845 published his article on "Homoepathy, Allopathy, and Young Physic." Since then the choice medical spirits of the two countries have been marching in opposite directions : the French gradually acquiring a steadily increasing faith in remedies and adopting our notions, Graves finding an enthusiastic admirer and translator in Trousseau; while we have now lived to see what must disturb the peace of Pereira in the blest abode-we have actually lived to see physicians, in metropolitan hospitals, treat acute rheumatism by mint-water, and boast of having done so. Now that we are all alive to the fact that the operations of nature cure alike the patients of quacks and of orthodox men, the cry is, "the natural history of diseases!" Very good; but it will take considerable time to write afresh the natural history of the most frequent diseases in our latitude, and what is to become of the patients in the meantime? Are we to tell them that we are uncertain whether medicines are useful, useless, or pernicious?

"The natural history of diseases" is a very good cry. It rang in my ears when $I$ was a medical student in Paris. Many wanted to begin medicine afresh, as they had to begin everything else, in the year 1 of the Republic, one and indivisible, It was the reproach of wise men to Louis that he ignored the legacy left us by the great of bygone ages, and was going to begin again to restore medicine, by his own individual efforts. Louis was a quiet gentleman, without a professorial platform he had neither the eloquence nor the audacity of a successful innovator. He persuaded some that the numeric method would save medicine; but he made no school, and his efforts did not in the least check the growing confidence in therapeutics.

"The natural history of diseases." A most laudable pursuit, repeatedly followed at different periods of history; but why talk of history to those who have so much to study that they cannot even read the history of their own art? I only profess to draw attention to what occurred in France after the collapse of Broussais, and I can aver that generally in the Paris hospitals expectation was the order of the day. Diet, simple tisanes, lavements (simple or medicated), castor oil, such was the general plan of treatment; sirop de diacode, if the patient did not sleep; leeches to cure local inflammation; moderate bleeding, if it were acute. Of course there might be found a Bouillaud attempting to jugulate pneumonia and typhoid fever, and some less known man treating typhoid fever by saline purgatives; but those who want to know the natural history of diseases will find it recorded in Andral's Clinique, and in the works of Chomel, Louis, and many other writers of the same time.

"The natural history of diseases !" I have insisted over and over again that the right way of studying diseases of women was to do so by the light of the natural history of menstruation, showing the way in one of my works. If for thirty years of her life woman is bled every month moderately, and often exorbitantly, with impunity, that should at least teach the present generation of medical men that it is absurd to be afraid of damaging a patient's constitution by taking away ten ounces of blood in cases of inflammation. The perfect innocuity of vomiting, in most cases of pregnancy, will some day teach medical practitioners how foolish it was to give up the use of emetics in many cases of dyspepsia and biliary derangement. If I take the liberty of pressing on others to hasten as much as possible the process by which they are attempting to make up their minds as to the extent of the powers of nature in the cure of disease, it is for the sake of our patients and for the credit of our art. It is no consolation to men of moderate opinions to know that when the pendulum of the human mind has violently swung in one direction it will assuredly, after a certain lapse of years, swing back with equal momentum in the opposite direction. There is so little rest between extremes; we have only just escaped from the reign of exorbitant doses and overstringent pharmaceutical formalism, and we are now menaced with a rapid return to that slough of expectant medicine which, centuries ago, was rightly stigmatised as " a meditation on death." Only a few years back and we were outrageously frightened by the bugbear of inflammation, and already our utility is often paralysed by the bugbear of debility.

Grosvenor-street, April, 1868.

\section{ON IMPROVED METHODS OF EXTRACTION} OF THE CATARACT.

By J. R. WOLFE, M.D., F.R.C.S. EdIN., OPHTHALAMTC SURGHON TO THE ABERDREN ROYAL IMPIBMARY.

No. I.

Mr object in these papers is, to submit to the profession the results of 96 cases of cataract, which $I$ have extracted by a new method; to compare this method with the ordinary flap extraction, and with the other procedures lately introduced by the German ophthalmologists. For a period of five years I tried these various methods in a considerable number of cases, in the public institutions with which I am connected, as well as in my private practice; but during the last three years I have adopted the procedure which I call "modified subconjunctival extraction," and which I find highly encouraging in its results.

In order to avoid a hasty generalisation, and to arrive at a satisfactory conclusion, I have not restricted my observations to the experience obtained within the scope of my own practice, but have frequently visited the different Ophthalmic Hospitals in this country and on the continent, with the view of seeing as many patients as possible at different stages; and it is only after a long study and comparison of the relative advantages and disadvantages of the different methods that $I$ venture now to recommend my modification to others for trial.

To give a connected view of the whole subject, it will be best to submit a short outline of the history of the operation of extraction, and to trace the different stages of its development. It will thus be interesting to see how we have progressed step by step in our course of improvement; how we have turned a hazardous operation - an operation fraught with anxiety to the surgeon and risk to the patient-into one of comparative ease and security.

The history of extraction of cataract can, according to Rhazes, be traced as far back as the end of the first century, when it was performed by Antyllus, and at a later period by Lathyrion. Ali-Abas, in the tenth century, knew also of the operation, and later, Abulkasem, having found it dangerous, tried to make the cataract disappear by suction, a method generally employed by the Persians. But if the operation ever was performed at that remote period, it had fallen into oblivion, and was practically unknown till 1707, when Saint-Yves, in the presence of Mery, made an incision in the cornea, and by means of a curette extracted a cataract, which, after depression, had risen up again, and passed through the pupil into the anterior chamber. The following year Pourfour du Petit performed the same operation upon a priest in the presence of Saint-Yves and Méry. The latter submitted an account of these operations to the Académie des Sciences, ${ }^{*}$ in which he proposed to extract a cataract through a corneal incision, not only when dislocated into the anterior chamber, but also when lying in situ behind the iris. As the author, however, never performed the operation which he so ingeniously suggested, his advice was fruitless, and nothing further was made known on the subject until the hint was reduced to practice, and the whole particulars of the process published by Daviel, a French surgeon, in 1745. + To Daviel, therefore, belongs the credit of having obtained that new conquest to science, in systematising

Mémoires de l'Académie des Sciences, 170?, p. 310

Daviel : Sur une Nonvelle Méthode de Guérir la Cataract par l'Extrac tion du Crystallin (Mémoire de l'Académie de Chirurgie, t. ii., p. 336, 4to ed., 
the process of extraction of the crystalline lens through an incision in the cornea. Daviel's procedure has subsequently been modified by Lafaye, Wenzel, Richter, Barthe, and Beer. It would be out of place here to mention all the modifications which Daviel's method has undergone; they refer partly to the size and direction of the flap, and partly to the form of the various instruments used.

Flap extraction. - The object of this operation, then, is the removal of the opaque crystalline lens from the eye, through the pupil, and through a semicircular opening made in the cornea, either in its upper or in its lower half. The incision must be made large enough to allow easy exit to the lens without the use of much pressure, which would do violence to the iris, or would rupture the hyaloid membrane and force out the vitreous humour. On the other hand, it must not be made too large, lest it should prevent coaptation of the flap and interfere with union by first intention. The size must be regulated by the nature and density of the cataract. If it has a hard large nucleus, the section should commence at the trans verse diameter of the cornea, the twentieth of an inch from its sclerotic junction, thus opening the half of its circumference but when the cataract is of a homogeneous softish consistency, or with a small nucleus, a section of five-twelfths of the circumference is sufficient, as such a cataract can mould itself and pass through a smaller opening. M'Kenzie advises to make the incision "at least one-half the circumference of the cornea," and mentions Ware as proposing even the ninesixteenth part.* After the incision is duly made, the anterior hemisphere of the capsule is to be lacerated as widely as possible with the cyctotome, and the lens to be gently squeezed out through the opening.

When this operation is well performed, and the healing process proceeds regularly, it leaves nothing to be desired; it is so beautiful in its results and appearance that it may be called the chef-d'ouvre of surgery. So high was my appreciation of this method, that three years ago, when exhibiting to the Aberdeen Medico-Chirurgical Society four of my first cases operated on by the modified sub-conjunctival method, I stated: "Of all the new methods which have lately been proposed for the extraction of cataract, none is, in my opinion, ever destined to supersede the ordinary flap extraction. Any given case of hard cataract without complications runs the best chance of sukcess by the old classic operation, which is, moreover, so brilliant in its results that I should never look for another operative procedure. But cases, like those which I have the honour of presenting to you, do occur which are associated with local or constitutional complications, rendering the old method either too hazardous or impossible. To overcome such difficulties we must devise new plans for the removal of the opaque lens.'

But it must be allowed that, besides the inapplicability of the flap operation to some cases, it carries a host of contingencies in its train. Not to mention the accidents which may occur during the operation, but which may be overcome by dexterity and coolness of judgment, there are others beyond the control of the operator, and which may undo his best executed work. It is evident that the ordinary flap extraction is inapplicable to a cataractous eye complicated with-1, an adherent pupil, with or without pseudo-membranous exudations; 2 , confluence of the vitreous humour (synchysis); 3 , dropsy of the anterior chamber (hydrophthalmus) ; 4, central opacity of, or conical cornea; 5, posterior staphyloma (sclerotico-choroiditis posterior) ; 6 , glaucoma. Moreover, as the patient is required, after such an operation, to remain perfectly quiescent for about four, six, or eight days, it is impracticable to those who are suffering from (1) rheumatism or sciatica, (2) disease of the bladder or bowels, (3) bronchitis, (4) bysteric or epileptiform attacks.

M. Desmarres tells of a patient, Baron V- (an important political personage), in whom, on examining the eye the third day after extraction, he found the sight good and the flap united; all on a sudden, when he was about to leave, the patient was seized with a fit of sneezing, which burst the flap, and the eye was completely destroyed. Every ophthalmic surgeon will be able to supply instances from his own experience where such an untoward accident as coughing, straining, starting, \&c., saddened his brightest prospects.

Let us briefly analyse the principal factors which render the operation per se hazardous, and see how we can eliminate them.

1. The large corneal incision requires some days before it heals, and a few additional days before the cicatrix is out of risk of being burst open. Now in a patient of strumous habit, * M'Kenzie: Practical Treatise on the Diseases of the Eye. 4th edit. p. 788 . or in a state of senile marasmus, such a large flap is apt to suppurate, independent of other contingencies or mal-coaptation; although it must be admitted that primary suppuration of the cornea is very rare indeed.

2. The lens may be found unnaturally adhering to the capsule -one of those cataracts which come slowly to maturity; and instead of coming out entire, the nucleus alone comes through, leaving the cortical substance in the equator of the eye, which no coaxing can entirely remove. The fragments which remain within the interstices of the capsule may cause proliferation of its epithelial cells and those of the membrane of Descemet, and thus act as a focus of inflammation. But,

3. The iris is the most fruitful source of subsequent mischief. The sphincter iridis sometimes contracts so much that the capsule cannot be sufficiently opened, or even after it had been opened the ixis may close upon the lens, preventing its easy exit; inordinate pressure is used, and contusion is the result. Now if this membrane has been wounded by the knife, or lacerated by the cyctotome, and particularly if it has been contused by undue pressure during the accouchement of the lens, a form of iritis develops itself, which may either close the pupil, or extend its infiammatory process to the wound, causing the latter to burst, and so produce hernia iridis and anterior adhesions, or it may even extend to the ciliary circle and to the deep membranes, causing panophthalmitis and complete destruction.

With so much anxiety did our classic writers caution us against lesion of the iris, which they considered as the startingpoint of nearly all the ills that befall the eye after extraction, that M'Kenzie's advice is, in case "the iris has fallen under the edge of the knife, an attempt must be made to push it back by pressing with the point of the forefinger on the cornea; but if the iris does not retire on pressure of the cornea, the knife must be withdrawn, and either the operation deferred to a future day, or a small probe-pointed knife introduced through. the aperture which has been made, pushed gently through the anterior chamber to the nasal edge of the cornea, and over the end of it an opening made with another knife, so as to allow it to come through, after which the incision is to be finished exactly in the same way as if the sharp-pointed knife only had been employed."* As far as I know, M. Desmarres was the first to advise us that when a fold of the iris has fallen upon the knife, it is better to run the knife through it ; for although in cases of contusion or laceration we must expect some misclitef, yet when a slice of the iris has been cleanly cut off, the healing process is far easier, and no iritis need be apprehended. This doctrine seems to me to contain the germ of many of the improvements which of late years have been introduced in ophthalmic operations.

\section{CLINICAL, ACCOUNT}

on

\section{CASES OF TRAUMATIC TETANUS;} WITH

\section{FURTHER REMARKS ON THE TREATMENT OF} THAT DISEASE WITH THE ORDEAL BEAN OF CALABAR.

By EBEN. WATSON, M.D., SURGEON TO THE ROYAL INTTRMARY, AND LECTURER ON PHYSTOLOGT IN ANDERSON'S UNTYERSITY, GLASGOW. (Conctuded from $p .435$. )

In must be acknowledged that much has yet to be done in the way of procuring a perfectly reliable form for the therapeutical administration of the bean. In the recent edition of the British Pharmacopcia, I perceive that the powder of the bean and the alcoholic extract are the only preparations men. tioned. In my earlier cases, and even for a long time in the preceding one, I employed a tincture made as recommended by Dr. Fraser, of Edinburgh, by percolation of the powdered bean with spirit; but I fear that this must be a preparation of very uncertain strength. And it was owing to this doubt that I changed it for the extract dissolved in spirit towards the end of the case just related. Eight grains of the former gradually rubbed down in and mixed with an ounce of spirits of wine, form a solution or tincture, every ten minims of which contain one-sixth of a grain of the extract. The dose can * M'Kenzie, op. cit., p. 795 . 